\title{
AN EPIDEMIC MYALGIA DISTINCT FROM BORN- HOLM DISEASE, WHICH CHIEFLY AFFECTED THE MUSCLES OF THE NECK*
}

\author{
By PAUL B. BEESON ANd T. F. McNAIR SCOTT \\ (From the American Red Cross Harvard Field Hospital Unit)
}

AT the present time Bornholm disease is the only recognised condition characterised chiefly by muscle pain which occurs in epidemic form. Indeed, the terms "epidemic myalgia" and "Bornholm disease" are used synonymously by many writers. Massell and Solomon ${ }^{1}$ (1935) have suggested, however, that the common condition of "stiff neck," or acute torticollis, represents another form of epidemic myalgia, and have reported the occurrence of fifty-two cases of "stiff neck" within three months in a group of three hundred persons, an attack rate of $17 \cdot 3$ per cent. Clinically their cases bore a close resemblance to those which are described in this communication. Smith ${ }^{2}$ (1937) reported a series of cases of "cervical myalgia" which occurred one winter among the boys at Rugby School, but he expressed the belief that these represented a form of Bornholm disease.

During the summer and fall of 1941 "stiff neck" seemed prevalent in various parts of Southern England. Accordingly, attempts have been made to accumulate accurate data on the incidence of this condition. The following is a description of a study carried out on a group of factory workers in November, 1941 .

\section{Method of Survey and Population Studied}

The population examined consisted of the employees of a piston-ring factory. The factory building, situated on the outskirts of a small city, contained one large machine room, dimensions 160 by 50 feet; an inspection room, 50 by 15 feet; and two small offices. At the time of the survey the employees were: two office workers, eleven inspectors, and one hundred and fifty machine workers; eighty-two of these persons were males and eighty-one were females. The work of the factory was done in two shifts, the members of the day-shift working from 7.30 a.m. to 7 p.m., those of the night-shift from 7.30 p.m.

\footnotetext{
* Received for publication December 10, 1941.
} 
to 7 a.m. During each shift there was a thirty-minute recess for tea and a sixty-minute lunch recess. These meals were eaten in the inspection room. Thus there was opportunity for rather close contact between all of the workers within each shift; but, on the other hand, there was little direct contact between the workers of the night-shift and those of the day-shift. The initial survey was made on November 19 by a group of public health nurses working under the supervision of the authors. Each employee of the factory was interviewed, and the information was entered on the following form:

$$
\text { Name. Age. Sex. Occupation. }
$$

Have you had any pain or stiffness in the neck or shoulders within the past six weeks?

If "Yes."

Date of onset.

Character of pain.

Location of pain (indicated on a diagram of the head and shoulders).

Ability to turn head.

Local soreness.

Did you have associated with it any of the following?

1. Headache. 2. General discomfort. 3. Fever. 4. Chilliness. 5. Common cold.

Measures of relief.

Symptoms aggravated by.

Duration of symptoms.

Did symptoms interfere with normal activities ?

What do you think caused them ?

Ever have this previously ?

How often ?

When ?

Were others affected at the same time?

Address since October 1.

Present residence.

Do you know anyone who has had " stiff neck" recently ?

If "yes," what is the association?

Date.

History taken by.

This form enabled the survey to be completed rapidly and without disturbance of factory routine. In cases where persons were experiencing symptoms at the time of the initial survey, follow-up inquiries were made. Because of the need for this information the study was continued for two weeks more than originally intended, thus covering a period of two months. 


\section{Results of SuRvey}

1. Attack Rate.-Of the one hundred and sixty-three persons questioned, a history of pain or stiffness in the neck or shoulder

Daily Incidence of Myalgia in Relation to Temperature

VARIATION AND RAINFALL.

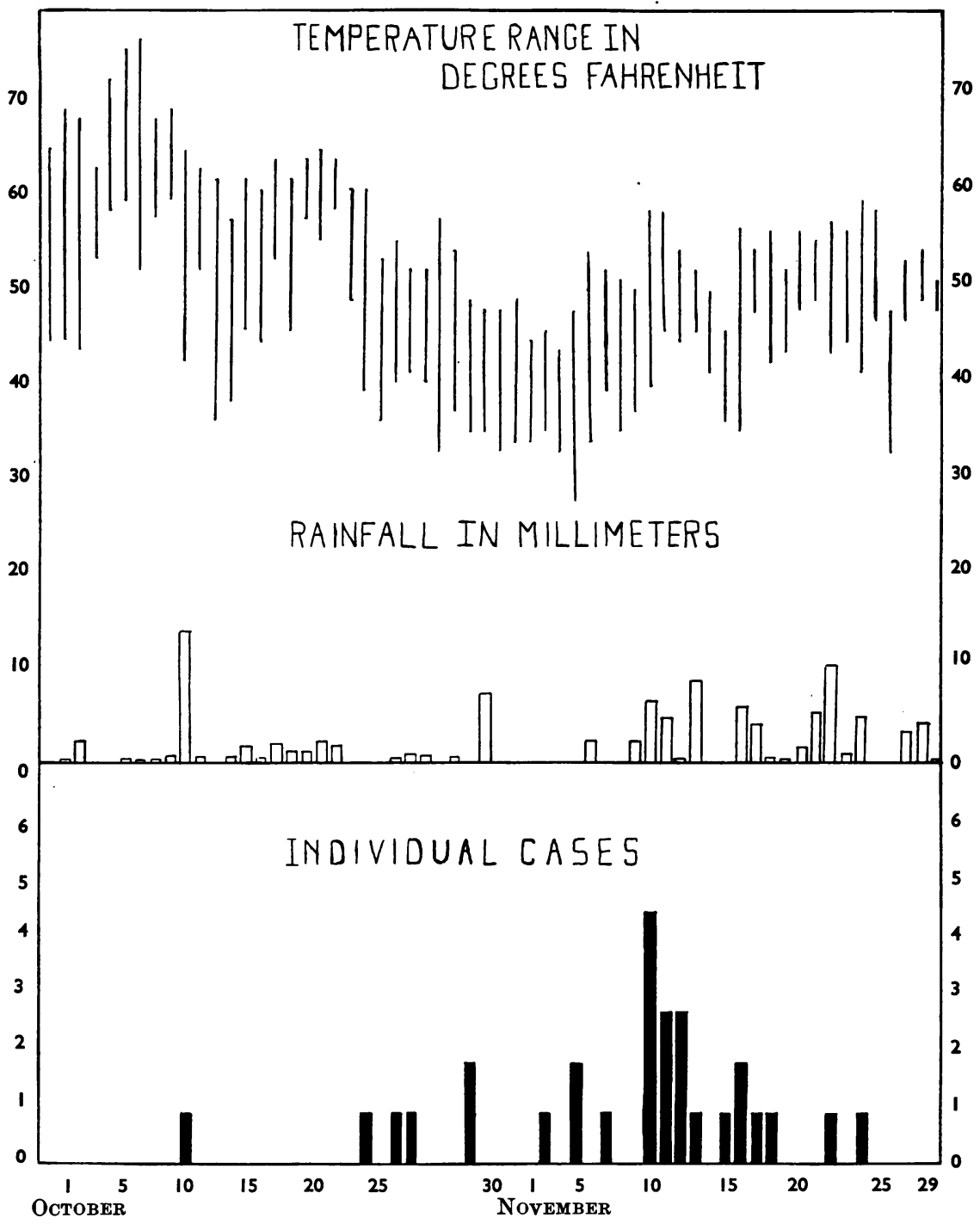

during the preceding two-month period was given by twentynine individuals-twelve males and seventeen females. This gives an attack rate of $17 \cdot 8$ per cent. 
2. Distribution of Cases in Relation to Date of Onset and the Weather.-The time relationship of the cases, according to the day of onset, is illustrated in Graph I and tabulated in Table I. Plotting the cases graphically gives a picture suggestive of an epidemic curve. The climatological data show that a period of cold weather preceded the time at which the case incidence was highest. The significance of this is not certain.

Table I.-Daily Incidence of Myalgia.* Date. Number of Cases.

\begin{tabular}{|c|c|c|c|}
\hline October & 10 & .. & . \\
\hline , & 22 & $\ldots$ & .. \\
\hline , & 24 & $\ldots$ & $\ldots$ \\
\hline , & 25 & $\cdots$ & . \\
\hline & 29 & $\ldots$ & $\ldots$ \\
\hline November & 3 & . & $\ldots$ \\
\hline , & 5 & $\ldots$ & $\ldots$ \\
\hline , & 7 & . & .. \\
\hline ," & 10 & $\ldots$ & .. \\
\hline , & 11 & . & .. \\
\hline ," & 12 & $\ldots$ & . \\
\hline ,, & 13 & $\cdots$ & .. \\
\hline , & 15 & $\cdots$ & .. \\
\hline , & 16 & $\cdots$ & . \\
\hline ," & 17 & $\cdots$ & . \\
\hline ," & 18 & $\cdots$ & . \\
\hline ," & 22 & $\cdots$ & .. \\
\hline & & & \\
\hline
\end{tabular}

3. Age and Sex Distribution.-As can be seen from Table II, the disease appeared to be more common in women than in men, seventeen cases among eighty-one, as compared with twelve cases among eighty-two, respectively. It should be pointed out that the age range of the two sexes is different, the average age of the women being twenty-six years, while that of the men was forty-two. From the small numbers studied in this particular population it is impossible to be certain whether the higher incidence of cases among women was due to a sex or age predilection of the disease.

4. Previous Attacks.-Fifteen of the twenty-nine affected persons gave a history of previous attacks; six of these had had one previous attack, and nine of them had had two or more. One man stated that he had suffered from "stiff neck" once a year for the past fifteen years. In five of the fifteen cases a previous attack had occurred during 1941, while five others had

* The survey and compiling of data were carried out by nurses of the Harvard Public Health Unit. 
been affected during 1940. Of the one hundred and thirty-five persons who did not have any symptoms during the two-month survey period, thirty-four gave a history of one or more attacks of "stiff neck" at some previous time.

Table II.-Distribution of Cases of Acute Myalgia in a Group of FACtory Workers, October aNd November, 1941.

\begin{tabular}{|c|c|c|c|c|c|c|c|}
\hline & \multicolumn{6}{|c|}{ Age Group in Years. } & \multirow[b]{2}{*}{ Total } \\
\hline & $10-19$ & $20-29$. & $30-39$ & $40-49$. & $50-59$. & $\begin{array}{l}60 \text { and } \\
\text { over. }\end{array}$ & \\
\hline $\begin{array}{l}\text { Males. } \\
\text { Number in each age } \\
\text { group }\end{array}$ & $\mathbf{l}$ & 10 & 19 & 34 & 12 & 6 & 82 \\
\hline Cases of myalgia & 0 & 0 & 4 & 6 & 1 & 1 & 12 \\
\hline $\begin{array}{l}\text { Females. } \\
\text { Number in each age } \\
\text { group }\end{array}$ & 11 & 52 & 12 & 3 & 2 & 1 & 81 \\
\hline Cases of myalgia & 3 & 11 & 2 & 0 & 1 & $\mathbf{0}$ & 17 \\
\hline $\begin{array}{l}\text { Total number of per- } \\
\text { sons in each age } \\
\text { group }\end{array}$ & 12 & 62 & 31 & 37 & 14 & 7 & 163 \\
\hline $\begin{array}{l}\text { Total number of cases } \\
\text { of myalgia in each } \\
\text { age group }\end{array}$ & 3 & 11 & 6 & 6 & 2 & 1 & 29 \\
\hline Per cent. & $25 \cdot 0$ & $17 \cdot 7$ & $19 \cdot 4$ & $16 \cdot 2$ & $14 \cdot 3$ & $14 \cdot 3$ & $17 \cdot 8$ \\
\hline
\end{tabular}

5. Type of Person Affected.-Consideration of the residences of the affected persons showed only that they came from widely scattered districts, with no evidence of case grouping. Two of the patients stated that there had been cases of " stiff neck" among their associates outside the factory within recent weeks, while similar information was obtained from five of the one hundred and thirty-five non-affected persons. No particular group of employees within the factory had been affected predominantly, since cases occurred among machine workers, inspectors and office workers (see Table III). This wide distribution

Table III.-Distribution of Cases According to Type of Work Done.

Classification.

Office workers ..

Inspectors ..

Machine workers $\quad \cdots \quad \cdots$

Totals
Number in Group.

$\begin{array}{r}2 \\ 11 \\ 150 \\ \hline 163\end{array}$
Cases of Myalgia.

$\begin{array}{r}2 \\ 1 \\ 26 \\ \hline 29\end{array}$

of cases among personnel doing various types of work is of interest in connection with the opinions of some of the patients 
mentioned below, who thought of the disease as a direct result of their work. No difference was found in the attack rates in the day- and night-shifts (see Table IV).

Table IV.-Attack Rate of Myalgia According to Factory Shift.

\begin{tabular}{lc|c|c|c}
\hline Factory Shift. & Number in Group. & Cases of Myalgia. & Attack Rate. \\
\hline Day . . &. & 99 & 18 & $18 \cdot 1$ \\
Night &. & 64 & 11 & $17 \cdot 2$ \\
\hline Totals &. & 163 & 29 & - \\
\hline
\end{tabular}

6. Patients' Opinions on Cause of Disease.-Persons who had suffered from "stiff neck" during the survey period were asked for their explanation of the cause. A classification of their answers is given in Table $\mathrm{V}$. Twenty of the twenty-nine persons blamed a "draught," five considered the condition due to the type of work done, one person ascribed it to the weather, and three persons said that they did not know.

Tabie V.--Causes of Myalgia as Given by the Patients.

\section{Causative Agents.}

Exposure to draughts

Type of work

Change in weather

Unknown

$\begin{array}{cccc} & & & \text { No. of Individuals. } \\ \ldots & \ldots & \ldots & 20 \\ \ldots & \ldots & \ldots & 5 \\ \ldots & \ldots & \ldots & 1 \\ \text { Total } & \ldots & \ldots & - \\ \end{array}$

\section{Clinical Features}

Certain details of the clinical disease were obtained from the histories and from observation of persons seen during the acute stage. In a typical case the appearance was characteristic; the head was held stiffly, and in looking to the side the eyes or body were turned instead of the neck. Invariably there was pain in some part of the trapezius muscle, although in some instances other muscles, such as the deltoid or sternomastoid, were also involved. The portions of the trapezius which were the most frequent sites of pain were: a point on the superior margin of the muscle midway between the occiput and acromion, the occipital attachment, and the portion adjacent to the lower cervical spine. In a few cases pain extended to other sites, such as the arm, forearm, lumbar and gluteal regions. Multiple sites of pain were the rule, sixty-two painful areas having been charted in the twenty-nine cases. Involvement of the right and left 
sides was almost equal (see Table VI). The pain was described as an "ache" by nineteen persons, as "sharp" by five, while the remaining five persons noted only a sensation of "stiffness."

Table Vi.-Location of Pain: 29 Cases of Myalgia.

\begin{tabular}{|c|c|c|c|c|c|}
\hline Right side only .. & $\cdot$ & & $\cdots$ & & $\begin{array}{ll}. & 7 \\
. & 3\end{array}$ \\
\hline Right side and midline & & . & $\cdots$ & & \\
\hline Left side only & & & $\cdot$ & & \\
\hline Left side and midline & . & . & . & $\cdot$ & $\cdots$ \\
\hline Midline only & . & -. & $\cdots$ & - & $\cdot$ \\
\hline Left and right sides & & .. & . & - & \\
\hline Left and right sides and & idline & $\ldots$ & $\ldots$ & & \\
\hline
\end{tabular}

Impairment of ability to turn the head was recorded in twentyone cases. Only sixteen of twenty-nine affected persons gave a history of local tenderness when questioned, but, from our experience, it seems probable that careful examination during the acute stage would always reveal such areas. Interference with normal activity - at work or at home-was experienced by twelve persons. Of these only two had consulted physicians, the others obtaining relief from such measures as bed rest, local heat and aspirin. The duration of symptoms was from one to four days in eighteen cases; from five to ten days in four cases; from ten to fourteen days in four cases; twenty-one days in one case; and in the two reported below symptoms were still present at the time of writing, having existed for three weeks and two weeks respectively. General symptoms were not a prominent feature, patients as a rule feeling nearly normal except for pain in neck or shoulder. Fifteen persons gave a history of headache; this seemed in some instances to have been related to pain in the trapezius near its occipital attachment. Twelve of the twenty-nine individuals stated that they had had a common cold at the time of their "stiff neck," while four gave a history of fever.

In two persons the disease took a more severe form. One was a man, thirty-eight years of age, who at the time of the survey had been confined to bed at home for nine days. His illness had begun with pain in the right side of the neck and inability to turn the head. Associated with this there had been some general malaise and weakness. In succeeding days the pain had extended down to the lumbar, gluteal and hamstring 
muscles on the same side. When interviewed again on December 2 he was out of bed, but still unable to work because of weakness and some residual pain. The other was a young woman of twenty-one, who was seen on November 22, the day of onset of her symptoms. At this time she described a dull aching pain in the region of the mid portion of the superior border of the left trapezius muscle. Pressure over the area caused pain. She held her head stiffly. There were no other complaints. She was seen again on November 24, when she was suffering from pain in the region of the left deltoid insertion. She also described numbness and tingling in the palm of her left hand, although there was no impairment of sensation by objective test. Blood examination showed a total leucocyte count of 10,200 per cu. mm., with 66 per cent. neutrophils, 33 per cent. lymphocytes, and 1 per cent. eosinophils. Erythrocyte sedimentation rate $(100 \mathrm{~mm}$. tube) was: $1 \mathrm{~mm}$. in fifteen minutes, $3 \mathrm{~mm}$. in thirty minutes, $9 \mathrm{~mm}$. in forty-five minutes, and $13 \mathrm{~mm}$. in sixty minutes. She had no elevation of temperature. The following day she complained of crampy pain in the arch of the left foot, and of "pins-and-needles" in that part. On November 26 the pain caused her to remain in bed at home. On November 28 she was transferred to the American Red Cross Harvard Field Hospital for further care. There was no fever, and she did not appear very ill. She still held her head stiffly. Areas of tenderness were found in the following parts: over the mid portion of the superior border of the left trapezius muscle, in the region of the insertion of the left deltoid, in the upper third of the flexor surface of the left forearm, and in the upper part of the left gluteus medius muscle. Physical examination was otherwise negative. Blood examination on December 1 showed: a total leucocyte count of 9,000 per cu. mm., of which 69 per cent. were neutrophils, 25 per cent. lymphocytes, 5 per cent. monocytes, and 1 per cent. eosinophils, Erythrocyte sedimentation rate was: $1 \mathrm{~mm}$. in fifteen minutes. $2 \mathrm{~mm}$. in thirty minutes, $4 \mathrm{~mm}$. in forty-five minutes, $5 \mathrm{~mm}$. in sixty minutes. Her symptoms decreased with rest in bed, but other areas of pain and tenderness appeared from time to time. One such, in the upper portion of the left rectus abdominis, caused pain when the patient attempted to raise her head from the bed, and on palpation this muscle appeared to be in spasm. At other times she complained of pain in the left upper extremity 
and in the left gluteal region. Sometimes these pains lasted only for an hour or two. By December 4 she was almost free of pain and was allowed out of bed.

\section{Discussion}

The syndrome under discussion appeared to be characterised by pain in various muscles, particularly the trapezius. In most cases the disease was confined to the muscles of the neck, the duration of symptoms was short, and the discomfort did not interfere with work or other activities. In certain individuals, however, the muscle pain was so severe as to cause considerable disability. There was little systemic disturbance, aside from headache, in about half of the cases.

The clinical features were unlike those of Bornholm disease, in which high fever, prostration, pleural and abdominal pain are so common. None of the patients observed in the present epidemic of myalgia suffered pleural pain. An additional difference was that the trapezius muscle was invariably involved in "stiff neck," whereas Sylvest ${ }^{3}$ (1934) found it affected only five times in seventy-two patients suffering from Bornholm disease. In contrast to the absence of similarity between this disease and epidemic myalgia of the Bornholm type, "stiff neck," especially in severe cases, resembles the common sporadic disease of acute fibrositis, in which the presence of localised areas of muscle tenderness, tingling sensations in the extremities, and lack of systemic symptoms are characteristic. This similarity is emphasised because fibrositis commonly involves the trapezius muscle. Copeman ${ }^{4}$ (1939) makes the following statement: " Fibrositis of the shoulder muscles, more especially the trapezius muscle, is probably the commonest rheumatic complaint met with in routine practice. . . . Diagnosis is easy. No organic signs of disease will be found. There will be pain of fairly sudden onset in one or both shoulders, often shooting up the neck or even down the arms, simulating perhaps brachial neuritis."

Acute fibrositis is not usually considered to be epidemic in nature, but further observations are desirable to determine whether such cases are always sporadic or may sometimes be associated with other similar cases, or with cases of " stiff neck." It is probable that epidemics of the latter are not uncommon, but that since most affected persons are able to continue with 
their routine activities and only the small number with severe or more generalised muscle pain come to the attention of physicians, epidemics cannot be detected without specific surveys.

\section{SUMmaRY}

1. A survey covering a period of two months was made to determine the incidence of "stiff neck" among a group of one hundred and sixty-three factory workers. Twenty-nine cases were discovered, an attack rate of $17 \cdot 8$ per cent.

2. The attack rate was higher in women, most of whom were in their third decade, than in men, most of whom were in their fifth decade.

3. Although the disease was usually mild, some persons were incapacitated for two weeks or longer.

4. The clinical features were unlike those of Bornholm disease but resembled those of acute fibrositis.

5. The purpose of the present communication is to direct attention to the occurrence of this syndrome in epidemic form.

\section{BIBLIOGRAPHY}

1. Massell, B. E., AND Solomon, R. (1935): New Eng. Journ. Med., 213, 399.

2. Sмiтн, R. E. (1937): Clin. Journ., 66, 331.

3. Sylvest, E. (1934): "Epidemic Myalgia" (Humphrey Milford, Oxford University Press, London).

4. Copeman, W. S. C. (1939): "The Treatment of Rheumatism in General Practice" (Edward Arnold, London, 3rd edition), p. 31.

\section{THE WELTMANN COAGULATION REACTION AND THE SEDIMENTATION TEST IN ARTHRITIS*}

\section{BY DAVID H. KLING†}

Two simple non-specific laboratory procedures are recognised to be of value in arthritis. One is the filament-non-filament leucocyte count (Eaton, ${ }^{1}$ Steinberg, ${ }^{2}$ Rawls $^{3}$ ). Steinbrocker and Hartung ${ }^{4}$ have found the non-filament count to be increased in

* Received for publication November 30, 1941.

+ From the Arthritis Clinic and Department of Laboratories, White Memorial Hospital, College of Medical Evangelists, Los Angeles, California. Appreciation is expressed for technical assistance to Miss Rope A. Stevensen, A.B., of the Dr. L. F. Pierce Laboratory, Los Angeles. 